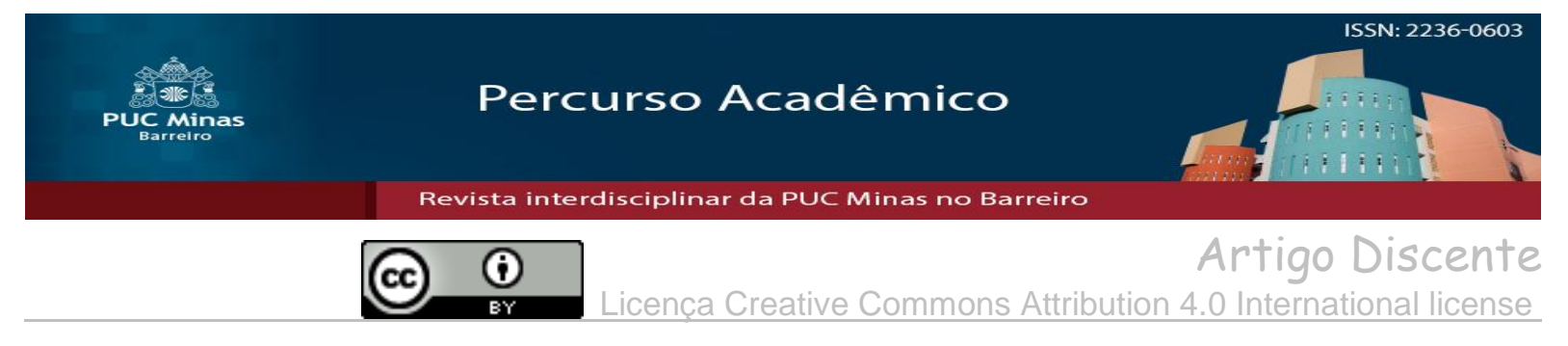

\title{
Transexualidade, violência e ciberespaço: um estudo etnográfico digital
}

\author{
Transsexuality, violence and cyberspace: a digital ethnographic study
}

\begin{abstract}
Bruno Rafael Silva Nogueira Barbosa ${ }^{1}$ Laionel Vieira da Silva ${ }^{2}$

\section{Resumo}

A sociedade brasileira estabeleceu normas para tentar enquadrar as pessoas em duas distintas categorias de gênero, marginalizando aqueles que não seguem os padrões idealizados. As pessoas transexuais, no entanto, rompem com tais normas, desafiando a lógica de um sistema binário. A pesquisa em questão trata-se de um estudo do tipo etnográfico digital. O objetivo desta pesquisa é analisar os discursos de cunho transfóbico de internautas, proferidos na seção de comentários de um site de notícia direcionados a uma jovem mulher transexual, vítima de violência doméstica. Esse estudo pode identificar algumas categorias que buscam naturalizar fenômenos sociais a favor de um pensamento excludente e inferiorizante da população trans. A internet mostra-se como um espaço para estudo e análise dos fenômenos da transfobia no contexto brasileiro, dado a sua variedade de participantes de diferentes grupos sociais, que emitem discursos sobre as matérias e notícias que leem na internet, reforçando pensamentos dentro e fora do ambiente digital.

Palavras-chave: Transexualidade. Lei Maria da Penha. Ciberespaço.
\end{abstract}

\begin{abstract}
Brazilian society has set standards to try to frame people in two different categories of gender, marginalizing those who do not follow the idealized standards. Transsexual people, however, break with such norms, challenging the logic of a binary system. The research in question is a study of the digital ethnographic type. The objective of this research is to analyze the speeches of transfobic nature of internauts given in the section of comments of a news site directed to a young transsexual woman victim of domestic violence. This study can identify some categories that seek to naturalize social phenomena in favor of an excluding and inferiorizing thinking of the trans population. The internet shows itself as a space for study and analysis of the phenomena of transphobia in the brazilian context, given its variety of participants from different social groups, who emit discourses about the stories and news they read on the internet, reinforcing thoughts inside and outside the world. environment.
\end{abstract}

Keywords: Transsexuality. Maria da Penha Law. Cyberspace.

\footnotetext{
Artigo recebido em 30 de Setembro de 2017 e aprovado em 25 de Abril de 2018.

${ }^{1}$ Graduando em Direito pela Universidade Federal da Paraíba. E-mail: bruno-dj15@ @otmail.com.

${ }^{2}$ Graduado em Psicologia, Especialista em Extensão Universitária e Desenvolvimento Sustentável, Mestre em Ciências das Religiões e Doutorando em Ciências das Religiões pela Universidade Federal da Paraíba. E-mail: laionel.vs@gmail.com.
} 


\section{Introdução}

A sociedade construiu diversos parâmetros e regras para todos os sujeitos, desenvolvendo conceitos e normas do ser "homem e mulher", pautados a partir estritamente do sexo biológico do indivíduo. Nesse momento se estabelece quais as pessoas que terão seus direitos efetivados, os que serão invisibilidades sociais e os destituídos de direitos fundamentais, como, por exemplo, educação, trabalho e a própria sobrevivência, simplesmente por não se "encaixarem" nesse modelo pré-concebido (BARBOSA, 2015).

$\mathrm{Na}$ contemporaneidade, a sociedade em geral, o Estado, as culturas midiáticas, as leis, a religião, a escola, dentre outras instituições, reiteradamente perpetuam em suas estratégias as matrizes identitárias tidas como referências e, consequentemente, fortalecem a re/produção das diferenças (OLIVEIRA JÚNIOR; MAIO, 2016, p. 160).

Entretanto, para entender o sujeito, torna-se necessário considerá-lo em seus diferentes aspectos sociais, biológicos e psicológicos na composição de sua formação identitária (MATÃO et al., 2010).

Rodrigues (apud MATÃO et al., 2010) afirma que a transexualidade por muito tempo foi tratada como desvio social, algo próximo à loucura, problemas de ordem mental ou mesmo compreendida erroneamente como sinônimo de homossexualidade.

As definições de "aberração", "loucura" ou "homossexualidade" ainda são aplicadas nos dias atuais para se referir socialmente às pessoas transexuais, como forma de deslegitimar a identidade de gênero dessas pessoas, tomando como embasamento preceitos religiosos fundamentalistas e biológicos para destituir o sujeito de humanidade.

A transfobia chega ao ciberespaço, assim como em todos os espaços de interação social. Essa desumanização das pessoas transexuais é banalizada e reforçada socialmente a partir desses discursos de ódio, tanto no ciberespaço quanto fora dele. Diversos crimes são cometidos contra essa população, de forma mais acentuada na população jovem. Muitas dessas pessoas não conseguem sequer chegar à fase adulta, fato esse ocasionado por diversos assassinatos, legitimados muitas vezes por discursos transfóbicos e ainda pela “invisibilização" desses crimes, tanto pelo poder judiciário quanto pela sociedade.

Assim, podemos perceber a importância das medidas protetivas para essa parcela da população socialmente vulnerável. A exemplo, podemos fazer referência à Lei Maria da Penha, que trouxe instrumentos “[...] importantes para assegurar uma intervenção preventiva do Estado a fim de evitar a ocorrência de delitos mais sérios contra a mulher, bem como para dar uma resposta mais efetiva à violência, visando assegurar a proteção integral nas relações de gênero" (ÁVILA, 2007). 
Nesses casos torna-se importante estabelecer que a jurisprudência e a doutrina têm compreendido que a Lei em questão também é aplicável a mulheres lésbicas, transexuais e travestis. Entretanto, também existem pessoas no poder judiciário que desconsideram a identidade de gênero do sujeito e aplicam a Lei de acordo com o sexo biológico, estando esses em desacordo com o avanço social e com o princípio da dignidade da pessoa humana, uma vez que as pessoas transexuais são alocadas em uma categoria distinta daquelas de gênero construídas socialmente.

Grande parte da sociedade persiste em acreditar na última corrente mencionada. Felizmente, os julgados e entendimentos estão seguindo a primeira corrente e aceitam a identidade de gênero para garantir o exercício de direitos básicos, como por exemplo, o uso do nome social, a retificação do nome civil e sexo e aplicação da Lei mencionada. Esses avanços não podem ser desconsiderados, mas trata-se ainda de meros paliativos.

“O Brasil é o único país do mundo onde, no vácuo de uma legislação geral, instituições garantem um direito negado globalmente. Aqui transmutamos o respeito à identidade de gênero em "nome social"” (BENTO, 2014, p.175). Em outros casos existem diversas barreiras burocráticas, no âmbito jurídico e médico, que dificultam o exercício pleno dos direitos garantidos constitucionalmente e negados socialmente, o que faz com que esses sujeitos possam ser compreendidos como "cidadãos precários":

A cidadania precária representa uma dupla negação: nega a condição humana e de
cidadão/cidadã de sujeitos que carregam no corpo determinadas marcas. Essa dupla
negação está historicamente assentada nos corpos das mulheres, dos/as negros/as,
das lésbicas, dos gays e das pessoas trans (travestis, transexuais e transgêneros).
Para adentrar a categoria de humano e de cidadão/cidadã, cada um desses corpos
teve que se construir como "corpo político". No entanto, o reconhecimento político,
econômico e social foi (e continua sendo) lento e descontínuo (BENTO, 2014,
p.167).

A sociedade ainda resiste em buscar a permanência da norma/relação entre sexo biológico e a identidade de gênero. Recentemente, com o aniversário de dez anos da Lei Maria da Penha, o site de notícias "G1" veiculou dez matérias com dez personagens em "comemoração à data".

Dentre essas personagens, foi contada a história de uma jovem transexual de 29 anos que sofreu violência doméstica do seu ex-companheiro. No hospital, outra violência foi cometida contra a jovem, desta vez não foi física mais sim contra a sua dignidade, sendo chamada pelo gênero masculino, mesmo após avisar ser uma mulher transexual e possuir um nome social condizente com a sua performance de gênero (MANTOVANI, 2016).

$\mathrm{Na}$ delegacia foi registrada a violência doméstica como agressão, onde se marcaria uma audiência que poderia demorar entre 30 e 60 dias. A jovem transexual conta que após 
saber do prazo da audiência e devido ao medo de ser assassinada, ela resolveu então fazer o relato do caso na rede social Facebook (MANTOVANI, 2016).

Um advogado se dispôs a me ajudar e me disse que não era só um caso de agressão física, era violência doméstica. E dentro da violência doméstica a lei para criminalização era a Maria da Penha. Foi a lei mais próxima do meu caso e serviu para estabelecer medidas protetivas para que ele não se aproxime de mim, já que me ameaçou (MANTOVANI, 2016).

No site do G1 encontramos, ao final de suas matérias, um espaço destinado a comentários de internautas sobre a notícia. A maioria desses comentários é feito de modo anônimo. Na notícia em questão foram direcionados 223 comentários dos quais a maioria possuía um teor transfóbico em seu discurso.

A partir dessa exposição, o presente trabalho possui como objetivo analisar os discursos de cunho transfóbico de internautas, proferidos na seção de comentários de um site de notícia direcionados a uma jovem mulher transexual ${ }^{3}$ que sofreu violência doméstica e teve o seu caso "enquadrado" na Lei Maria da Penha.

Compreendemos os comentários com embasamento na teoria ator-rede, "[...] como rastros que deixam pistas acerca de preferências, preconceitos e performances de gosto" (LATOUR apud LIBARDI, 2015, p. 181), para que assim possamos entender como se encontra a percepção sobre os casos de aplicação da Lei em questão às mulheres transexuais e travestis, no judiciário e na sociedade.

\section{Metodologia}

Neste trabalho foi empregada a etnografia digital. Hine (2005) aponta a possibilidade de aplicabilidade da etnografia também no ciberespaço, tendo em vista que esse é um espaço pertinente para pesquisas etnográficas, no qual é possível compreender a socialização de diferentes pessoas, bem como a expressão destas frente a determinados temas, conectadas através da internet.

Podemos sugerir, então, que uma mudança metodológica, a reivindicação do contexto online como um local de campo etnográfico, foi crucial para estabelecer o status das comunicações de Internet como cultura. Enquanto experimentos psicológicos demonstraram a sua escassez, métodos etnográficos foram capazes de demonstrar a sua riqueza cultural. É possível ir mais longe e sugerir que o nosso conhecimento da Internet como um contexto cultural está intrinsecamente ligada à aplicação da etnografia. O método e o fenômeno definem um ou outro, numa relação de dependência mútua. $\mathrm{O}$ contexto on-line é definido como um contexto cultural pela demonstração de que a etnografia pode ser aplicada a ele. Se podemos estar confiantes de que a etnografia pode ser aplicada com sucesso a contextos on-line, então podemos ter a certeza de que estes são, de fato contextos culturais, uma vez

3 Disponível em: http://g1.globo.com/politica/noticia/2016/08/tenho-muito-medo-de-ele-me-matar-diztransexual-espancada-pelo-ex.html. 
que a etnografia é um método para a compreensão da cultura (HINE, 2005, p. 9, tradução nossa) ${ }^{4}$.

Os discursos aqui analisados foram selecionados por possuir um teor transfóbico dirigido a uma jovem transexual que teve o seu caso de violência doméstica "enquadrado" na Lei Maria da Penha. Os outros discursos proferidos foram excluídos do presente estudo por não possuírem relevância para a pesquisa.

Esses comentários foram categorizados em dois diferentes eixos: "naturalização dos gêneros" e "lei cisgênero". Os internautas tiveram seus nomes substituídos por uma ordem numérica de 1 a 8, de acordo com a ordem que aparecem neste trabalho.

\section{Notas introdutórias à temática}

O estudo da temática sobre gênero no Brasil, mais especificamente os estudos sobre a mulher, teve sua emergência nos anos de 1970 (MATOS, 1998). Nesta mesma década, o movimento feminista ${ }^{5}$, ocupando um espaço de maior expressão se articulou com diversos outros movimentos sociais como: a luta por moradia, movimentos políticos como o movimento pelo direito à terra de grupos indígenas e movimento dos homossexuais (CORRÊA, 2001).

Já nos anos de 1980, no espaço da produção historiográfica brasileira sobre as mulheres, se analisou, a partir de diversas abordagens, a questão da mulher. Esse fato possibilitou a recuperação de poderes e lutas das mulheres, assim como permitiu que mitos fossem examinados e que estereótipos fossem repensados (MATOS, 1998).

Num leque de várias correntes de interpretações, procurou-se recuperar a atuação das mulheres no processo histórico como sujeitos ativos, de modo que as imagens de pacificidade, ociosidade e confinação ao espaço do lar foram questionadas, descortinando-se esferas de influência e recuperando os testemunhos femininos (MATOS, 1998, p. 68).

Os estudos de gênero e feministas brasileiros tiveram seu início marcado pelas urgências sociais existentes na época e foram usados como "norte/orientadores" para os

4 We might suggest, then, that a methodological shift, the claiming of the online contexto as an ethnographic field site, was crucial in establishing the status of Internet communications as culture. While psychocological expriments demonstrated its paucity, ethnographic methods were able to demonstrate its cultural richness. It is possible to go further and to suggest that our knowledge of the Internet as a cultural context is intrisically tied up with the aplication of ethnography. The method and the phenomenon define one another in a relationship of mutual dependence. The online context is defined as a cultural context by the demonstration that ethnography can be applied to it. If we can be confident that ethnography can successfully be applied to online contexts then we can rest assured that these are indeed cultural contexts, since ethnography is a method for understanding culture (HINE, 2005, p. 8).

${ }^{5} \mathrm{O}$ feminismo é uma filosofia que reconhece que homens e mulheres têm experiências diferentes e reivindica que pessoas diferentes sejam tratadas não como iguais, mas como equivalentes (FRAISSE, 1995; JONES, 1994; LOURO, 1999; SCOTT, 1986 apud NARVAZ; KOLLER, 2006, p. 648). 
objetivos tais estudos. Possuíam como interrogações primordiais preocupações como família, trabalho e política (SCAVONE, 2008).

Marcados pelas ressonâncias das lutas por redistribuição, justiça e direitos políticos e sociais e/ou por lutas pelo reconhecimento e/ou identitárias, os estudos de gênero e feministas mostraram-se historicamente comprometidos com a transformação das relações de dominação e poder masculinos associando-as a contextos mais abrangentes. Buscaram compreender os problemas que constituem as relações de gênero na sociedade, trazendo-os para o debate e a reflexão política e social mais amplos, associando-os, em determinadas análises, à classe e à raça, especialmente no Brasil e no restante da América Latina (SCAVONE, 2008, p. 176).

O movimento feminista contemporâneo, assumindo uma perspectiva diferenciada, se desenvolveu significativamente transbordando as visões de um movimento estritamente relacionado à classe média e branca, para os demais segmentos sociais, embora com muitas demandas em comum (NARVAZ; KOLLER, 2006).

As feministas destacam que a opressão de gênero, de etnia e de classe social perpassa as mais variadas sociedades ao longo dos tempos. Esta forma de opressão sustenta práticas discriminatórias, tais como o racismo, o classismo, a exclusão de grupos de homossexuais e de outros grupos minoritários (NEGRÃO, 2002; PRÁ, 1997; TOLEDO, 2003 apud NARVAZ; KOLLER, 2006, p.648).

As opressões de gênero construídos com base em um "binarismo dos gêneros" e em uma "hierarquia dos gêneros" (LOURO, 2014), acabam também sustentando diversas outras opressões a diferentes grupos marginalizados, minoritários e invisibilizados.

O binarismo construído socialmente também é utilizado como fonte de legitimidade de um sistema simplista de vagina-mulher e pênis-homem (BENTO, 2008); além de uma suposta existência de um binômio de gênero (mulher e homem) que também se naturaliza e constrói uma "imagem" social do que é ser cada um desses "corpos".

A mulher legitimada por esse sistema é pensada como possuidora de uma feminilidade natural. A existência desse ser se caracterizada por uma biologia determinista que direcionaria este sujeito ao polo "feminino" do binarismo. Juntamente com essa designação, a esse ser também é "imposto" características supostamente inerentes ao ser mulher.

Esses mesmos "mecanismos sociais" de imposição de características dos gêneros também são presentes no sujeito caracterizado como homem, entretanto, com aspectos opostos ao do ser mulher. Nesse sentido o conceito de "performatividade de gênero", forjado pela filósofa norte-americana Judith Butler, em sua obra Problemas de gênero - feminismo e subversão da identidade (1990) é bastante elucidativo "[...] a performatividade deve ser compreendida não como um "ato" singular ou deliberado, mas, ao invés disso, como a prática 
reiterativa e citacional pela qual o discurso produz os efeitos que ele nomeia" (BUTLER, 2000, p. 111).

A autora menciona que "o entendimento da performatividade não como o ato pelo qual o sujeito traz à existência e aquilo que ela ou ele nomeia; mas, ao invés disso, como aquele poder reiterativo do discurso para produzir os fenômenos que ele regula e constrange" (BUTLER, 2000, p. 111). Então, podemos compreender a "“[...] performatividade não como um ato pelo qual o sujeito se torna o que ele/ela nomeia, mas como este reiterativo poder do discurso para produzir o fenômeno que regula e obriga" (AMARAL, 2007, p. 45).

Essa norma que regula os corpos e define socialmente uma dualidade de gênero, produz diversas outras opressões. Com essa concepção de gênero surge uma "completude" natural. O "corpo masculino" se torna complemento do "corpo feminino", se construindo assim uma sociedade heteronormativa, definindo como regra uma "heterossexualidade compulsória" (RICH, 2010).

Dessa forma, a norma apresentada determina, com base no sexo biológico, o gênero supostamente apropriado ao sujeito. Esse "direcionamento" é definido antes mesmo do nascimento. A partir da ultrassonografia, o indivíduo já é definido como menina ou menino tomando como parâmetro a aparência externa do órgão sexual. Como afirma Bento (2008), a tecnologia acaba por produzir os gêneros.

Porém, foi com o conceito de gênero direcionado ao feminismo que foram possibilitadas novas compreensões para a construção das identidades de gênero, não se restringindo a apenas um modelo universal de mulher (BENTO, 2006 apud JESUS; ALVES, 2010).

\footnotetext{
A partir das novas ideias e comportamentos trazidos com o movimento feminista, a percepção sobre quem são as mulheres se ampliou, deixou de apenas se remeter à mulher branca, abastada, casada com filhos, e passou a acatar a humanidade e a feminilidade de mulheres outrora invisíveis: negras, indígenas, pobres, com necessidades especiais, idosas, lésbicas, bissexuais, solteiras, e mesmo as transexuais (JESUS; ALVES, 2010, p. 12).
}

Nesse momento, o sentido de ser mulher ganha maior completude, pois passa a abarcar os sujeitos diversos dos socialmente definidos enquanto mulher, ou seja, ultrapassa a ideia normatizada de mulher branca cis-heteronossexual de classe média, contemplando dessa forma as diversas especificidades, que atenta aos marcadores sociais de diferença. 


\section{Violência contra a população trans}

Os indivíduos que possuem uma identidade de gênero em acordo com o seu sexo biológico, acordo esse definido socialmente, são chamadas de pessoas cisgênero ${ }^{6}$. Já as pessoas que fogem a esse "determinismo biológico", ou seja, que não possuem uma concordância do seu sexo biológico com a sua identidade de gênero são as pessoas transgênero ${ }^{7}$.

Esse "desvio" da norma acaba por produzir invisibilidade a essa população, marginalizando e destituindo-a de direitos consagrados na própria Constituição Federal, lei maior de um Estado democrático de direito.

Essa diferença é usada como arma política com o intuito de não efetivar direitos, esse sistema acaba por conferir e definir quem terá resguardado os seus direitos. Com isso os que fogem à regra dicotômica do sistema binário e heteronormativo acabam tendo avariado os seus direitos à medida que estes não se efetivam, possuindo apenas uma existência nos textos jurídicos, ou seja, há uma diferença entre o "dever ser" e o "ser", entre o "ter o direito" e o "ter efetivado esse direito" (BARBOSA, 2015, p.165).

O direito à vida da população trans está sendo cerceado. A transfobia está matando vários indivíduos, simplesmente por não possuírem uma identidade de gênero em acordo com o seu sexo biológico. Dados recentes da Transgender Europe's Trans Murder Monitoring ${ }^{8}$ (TMM) demostraram que cerca de 50\% dos assassinatos de pessoas transexuais ocorreram no Brasil entre 2008 e $2014^{9}$.

Esses dados demonstram a vulnerabilidade e a importância de se proteger e resguardar os direitos dessa população. A expectativa de vida, segundo estimativas da ANTRA, para travestis no Brasil é em torno de 30 anos. Essa baixa expectativa de vida decorre de diferentes fatores como o preconceito e violência contra elas, levando essa parcela da população a uma expectativa de vida a metade da população Cis (BARBOSA, 2015, p. 167).

As pessoas transexuais possuem uma expectativa de vida significativamente inferior aos das pessoas cis. Esse fato se dá pela grande violência marcada por uma discriminação contra essas pessoas, ou seja, assassinatos motivados por transfobia. Essa baixa expectativa de vida para as pessoas trans também decorre do alto índice de assassinatos de jovens dessa categoria.

\footnotetext{
${ }^{6}$ Conceito "guarda-chuva" que abrange as pessoas que se identificam com o gênero que lhes foi determinado quando de seu nascimento (JESUS, 2012, p. 14).

7 Conceito "guarda-chuva" que abrange o grupo diversificado de pessoas que não se identificam, em graus diferentes, com comportamentos e/ou papéis esperados do gênero que lhes foi determinado quando de seu nascimento (JESUS, 2012, p. 14).

${ }^{8}$ Observatório europeu de monitoramento de assassinato de transexuais (Tradução livre do autor).

${ }^{9}$ Disponível em: http://tgeu.org/tmm-idahot-update-2015/
} 
Ainda de acordo com dados do observatório europeu de monitoramento de assassinato de transexuais, $12 \%$ dos assassinatos de pessoas transexuais no mundo, entre o período de 2008-2014, situa-se entre os 8 e 20 anos e $44 \%$ entre 20 e 29 anos. Não foi recolhido por esse observatório dados de faixa etária das/dos transexuais assassinadas no Brasil, porém, relata-se um caso de assassinato de uma menina trans de 8 anos ocorrido no seio familiar, na cidade do Rio de Janeiro.

Nos últimos sete anos, 131 pessoas trans e de gênero-diverso com menos de 20 anos de idade foram assassinadas segundo relatado, representando $12 \%$ de todos os assassinatos relatados onde a idade era conhecida. Quarenta e oito destes 131 vítimas tinham menos de 18 . Uma extrema tendência preocupante é o fato de que nos últimos dois anos cinco pessoas trans menores de 14 anos foram assassinadas segundo relatado: entre os 10 assassinatos de menores em 2014 havia uma menina trans de 8 anos de idade, que foi espancada até a morte em 18 de fevereiro de 2014 no Rio de Janeiro, Brasil, por seu pai, que queria ensiná-la a se comportar como um homem ${ }^{10}$ (Tradução livre).

Já de acordo com dados do Grupo Gay da Bahia (GGB), 343 pessoas da população LBGT foram assassinadas no Brasil no ano de 2016, contabilizando um crime de ódio contra essa parcela da população brasileira a cada 25 horas. No ano em curso, 2017, o grupo por meio do site "Homofobia mata" já contabilizou 296 assassinatos de pessoas LGBT, no Brasil. Em 2016, das 343 pessoas assassinadas, "173 eram gays (50\%), 144 (42\%) trans (travestis e transexuais), 10 lésbicas (3\%), 4 bissexuais (1\%), incluindo 12 heterossexuais, como os amantes de transexuais ("T-lovers"), além de parentes ou conhecidos de LGBT que foram assassinados por algum envolvimento com a vítima, como o ambulante ${ }^{11}$ do metrô de S. Paulo ou por serem confundidos com gays" (GGB, 2016, p. 01-02).

\begin{abstract}
Proporcionalmente, as travestis e transexuais são as mais vitimizadas: o risco de uma "trans" ser assassinada é 14 vezes maior que um gay, e se compararmos com os Estados Unidos, as 144 travestis brasileiras assassinadas em 2016 face às 21 trans americanas, as brasileiras têm 9 vezes mais chance de morte violenta do que as trans norte-americanas. Segundo agências internacionais, mais da metade dos homicídios de transexuais do mundo, ocorrem no Brasil (GGB, 2016, p. 02).
\end{abstract}

Ainda de acordo com os dados levantados por esse grupo, $32 \%$ das pessoas LGBT, assassinadas em 2016, possuíam entre 19-30 anos, 7,2\% das vítimas eram da terceira idade e cerca de 20,6\% possuíam menos de 18 anos. O relatório ainda afirma que existe uma grande

\footnotetext{
${ }^{10}$ In the last seven years, 131 trans and gender-diverse persons under 20 years of age have been reported murdered, accounting for $12 \%$ of all reported murders where the age was known. Forty-eight of these 131 victims were under 18. An extremely distressing tendency is the fact that in the last two years five trans people under 14 have been reported murdered: among the 10 murdered minors in 2014 were an 8-year-old trans girl, who was beaten to death on February 18th 2014 in Rio de Janeiro, Brazil, by her father, who wanted to teach her to behave like a man (TMM, 2015, s.p.).

${ }^{11}$ No Metrô de São Paulo no dia do Natal, o vendedor ambulante Luiz Carlos Ruas, foi massacrado até à morte, quando tentava defender um gay e uma travesti perseguidos por dois lutadores marciais (GGB, 2016, p. 1).
} 
vulnerabilidade para essa população, "grande vulnerabilidade de nossos/as adolescentes, sobretudo das jovens travestis e transexuais profissionais do sexo" (GGB, 2016, p. 03).

A impunidade fica visível quando observamos os dados apresentados. O relatório ainda afirma que apenas $17 \%$ dos assassinatos tiveram o criminoso identificado (60 dos 343), e menos de $10 \%$ desses assassinatos resultaram em abertura de processo e em punições dos assassinos (GGB, 2016). Esses números nos revelam os altos índices de assassinatos de jovens transexuais, que segundo o GGB, essa impunidade estimularia novos ataques à população LGBT.

\section{Resultados e discussão}

A internet se destaca como um espaço importante de interação social propícia a diversos diálogos, comentários e discursos, que também podem possuir um teor de preconceito dirigido a grupos socialmente vulneráveis.

Bastam alguns minutos conectados ao Facebook, WhatsApp, entre outras
plataformas para notar que as redes sociais estão repletas de explicações mágicas,
polêmicas, antidiálogo e, sobretudo, aversão ao que é diferente. As seções de
comentários dos maiores portais de internet do Brasil estão repletos de hostilidade e
ódio a qualquer opinião que não agrade a visão de mundo de quem lê (CALIXTO,
2015, p. 07).

Esses comentários produzem "resultados e consequências" no espaço dentro e fora da internet (online e off-line) "Devido à reprodução sistemática de discursos hostis no ambiente online, eles acabam sendo socialmente aceitos primeiramente para discriminar e, em um segundo momento, para oprimir determinados grupos de pessoas" (PARKS apud LIBARDI, 2015, p. 182).

Esses discursos "proferidos" no ciberespaço acabam "naturalizando concepções transfóbicas" em toda a sociedade, seja no ciberespaço ou fora dele.

\footnotetext{
Assim, conclui-se que a condição de subcidadania das pessoas transexuais envolve muitas questões, dentre as quais, o poder que concepções naturalizadas têm de produzir e reproduzir situações que, se por um lado privilegiam alguns grupos, por outro, marginalizam aqueles que simplesmente são diferentes da norma, como é o caso das/dos transexuais (JESÚS, 2011, p. 02).
}

Torna-se, então, muito relevante compreender esses discursos oriundos do ciberespaço que buscam deslegitimar o status de cidadã e cidadão da pessoa transexual, marginalizando e excluindo esses sujeitos. O desrespeito à identidade da pessoa transexual é usada constantemente como forma de deslegitimar a aplicabilidade da legislação para elas, como por exemplo, em alguns casos em que são negadas as medidas protetivas estabelecidas pela lei Maria da Penha. 
Buscando sistematizar e melhor compreender os discursos proferidos pelos internautas aqui analisados, foram selecionadas duas categorias denominadas "Naturalização dos Gêneros" e "Lei cisgênero", decorrentes dos discursos, possibilitando o agrupamento desses comentários nesses dois eixos.

\title{
5 Naturalização dos gêneros
}

A primeira categoria aqui descrita, "Naturalização dos gêneros", caracteriza-se como um espaço onde se pretende agrupar discursos colhidos dos internautas pesquisados que possuem um determinismo biológico, concebendo os gêneros a partir de uma correlação deste com o sexo designado ao sujeito no nascimento.

Para embasar este grupo, tomamos como alicerce os pressupostos construídos por Jesús (2011), que afirma que a sociedade construiu alguns conhecimentos com base em acepções de natureza, dentre estes estão as noções de gênero e sexualidade, vistas como elementos predeterminados e fixados pela biologia.

\begin{abstract}
Uma vez que se entende como natural aquilo que traz em si algo de inerente, de próprio, de uma essência que faz com que uma coisa seja o que ela é, tanto naturalizar quanto desnaturalizar são situações que não ocorrem de fato, pois não é possível inserir uma essência em algo, ou por outro lado, destituí-lo de uma. No sentido aqui empregado, naturalizar significa atribuir qualidades essenciais ao que na verdade é fruto de atividades humanas [...] (JESÚS, 2011, p. 02).
\end{abstract}

A natureza é embasamento presente nos quatro comentários analisados nessa categoria. Os internautas 1 e 2 buscam com seus discursos deslegitimar a identidade de gênero da jovem mulher transexual, baseados em uma natureza como "construtora" dos gêneros. Para estes, ou se nasce "homem" com um pênis ou se nasce "mulher" com uma vagina.

\section{Internauta 1: OU É OU NÃO É....A NATUREZA NÃO ERRA....QUEM ERRA É O SER HUMANO, COM SUA SAFADEZA SEM FIM E SEM LIMITES...}

Internauta 2: Eu fui formado e saí de dentro de uma mulher e posso garantir que essa aberração não é uma mulher.

Observa-se, então, um pensamento transfóbico estritamente baseado em uma leitura binária de gênero, que infelizmente encontra-se de acordo com o que "está socialmente estabelecido para as pessoas, numa perspectiva biologicista e determinista, há duas - e apenas duas - possibilidades de locação das pessoas quanto à anatomia sexual humana, ou seja, feminino/fêmea ou masculino/macho" (PETRY; MEYER, 2011, p. 195).

O internauta 2 ainda legitima o seu discurso com uma definição de mulher como aquela que possui a possibilidade de gerar filhos. Justifica esta concepção, ao afirmar que nasceu de uma mulher e por esse motivo sabe o que é "ser mulher". O internauta desconsidera qualquer mulher que não possa engravidar; excluindo nesses casos também até as próprias 
mulheres cisgêneros que ele busca legitimar em seu discurso, como as únicas mulheres "verdadeiras".

O gênero é, portanto, idealizado erroneamente pelos internautas, como sinônimo de um sexo biológico designado ao nascer. Tal afirmação está enraizada no pensamento característico da transfobia (BARBOSA; SILVA, 2016).

A "natureza não erra" e "essa aberração não é mulher", trechos proferidos pelos internautas, remetem a ideia à norma cis, no qual aqueles/aquelas que não se adequam à essa normatização passam a ser considerados erros de uma suposta ordem natural binária, que elege como aberração os sujeitos considerados desviantes.

Internauta 3: Se eu tivesse uma mulher fake dessas, eu também mandaria o sarrafo todo dia.

Já o internauta 3 constrói, em sua afirmativa, um conceito de "mulher fake", ou seja, uma mulher que não é mulher, mas que imita uma. Essa "imitação de mulher" seria pelo fato da mulher transexual não possuir uma concordância entre o seu sexo biológico e a sua identidade de gênero, que para este internauta seria uma justificativa para a violência física diária contra ela.

Existe, nesse caso, a atribuição do pensamento binário (BENTO, 2008): elege-se como única possibilidade o homem e a mulher, com suas atribuições específicas de corpo e comportamentos, considerando inclusive a identidade cis como "original".

Internauta 4: Não consigo entender, embora respeitando o direito de cada um acho que é contra a natureza de Deus que coisa estranha.....

O internauta 4 afirma que compreende que as pessoas transexuais estão indo contra a natureza de Deus, desconsiderando a identidade da jovem e tomando como pressuposto único e verdadeiro as suas concepções religiosas. Entretanto, ainda comenta que respeita o direito de cada pessoa, mesmo depois de desconsiderar o direito a existência da jovem ao negar a sua identidade de gênero.

Tal naturalização é presente na literatura científica quando se trata de questões de ordem religiosa fundamentalistas, mais especificamente de interpretações de teor religioso acrescido de preconceito (BARBOSA; SILVA, 2016).

A fala do internauta 4 revela ser a transexualidade como algo "contra a natureza de Deus", acrescenta assim um teor divino na legitimação da naturalização do gênero, pensado a partir de sua própria interpretação. 
Os comentários dos internautas revelam a existência de um preconceito transfóbico que se baseia na concepção de gênero como natural, desrespeitando a existência das pessoas de identidade diferente da norma cis imposta.

\section{Lei cisgênero}

Outra categoria que emergiu desta pesquisa foi denominada de "Lei cisgênero", sendo fundamentada com base no conceito de cisgênero construído por Jésus (2012, p. 14). Para essa autora, o termo pode se entendido como um "Conceito 'guarda-chuva' que abrange as pessoas que se identificam com o gênero que lhes foi determinado quando de seu nascimento".

Nesse sentido, essa categoria agrupa os discursos que buscam definir a pessoa que será resguardada por uma lei que visa acabar/diminuir com a violência contra a mulher. Esse sujeito então será a mulher cisgênero, excluindo as outras mulheres da possibilidade de proteção dessas Leis, como por exemplo, a Lei Maria da Penha e Lei do feminicídio.

Os internautas 5 e 6 afirmam que as agressões ocorreram entre dois homens, não existindo então mulher envolvida e, portanto, segundo a compreensão destes, as medidas protetivas, estabelecidas pela Lei Maria da Penha, não deveriam ser usadas nesse caso. Ambos restringem a concepção de mulher apenas àquelas que foram determinadas enquanto mulher ao nascer, desconsiderando o gênero das mulheres transexuais, buscando legitimar a Lei apenas para as mulheres cisgênero.

Internauta 5: Os caras saíram no braço, ai te pergunto, o que a lei Maria da Penha tem a ver com isso?? Eu hein.

Internauta 6: não entendo essa lei Maria da Penha...... NÃO É VÁLIDO SOMENTE PARA MULHER?????

Ambos os internautas consideram a Lei Maria da Penha válida apenas para mulheres cisgênero, desconsiderando a sua aplicabilidade para a população trans. Para estes ocorre um entendimento errôneo, pois não se trata de uma lei exclusiva para mulheres cis (BARBOSA, 2015).

Os discursos proferidos pelos internautas 7 e 8 seguem na mesma direção dos anteriores, eles defendem a aplicação apenas a mulheres cisgênero.

Internauta 7: Porque um homem que dá o toba vítima de agressão a lei tem diferente dos "normais"? As leis estão ficando relativas. A lei tem ser igual pra todos.

Internauta 8: Pensei que Maria da Penha era para defender mulheres não aberrações comportamentais. 
Nos dois casos acima, também é possível perceber a presença do pensamento de lei cisgênero. Pela compreensão do internauta 7, a lei deveria ser pensada pelos valores dominantes da identidade cis, já para o internauta 8, a questão torna-se mais impactante, atribuindo as pessoas trans a ideia de "aberrações comportamentais".

O internauta 7 ainda considera que a Lei está sendo "relativa" por ser aplicada a mulheres transexuais, que este considera homem. Entretanto, Dias (2008, s.p.) assegura que:

No momento em que é afirmado que está sob o abrigo da lei a mulher, sem se distinguir sua orientação sexual, alcançam-se tanto lésbicas como travestis, transexuais e transgêneros que mantêm relação íntima de afeto em ambiente familiar ou de convívio. Em todos esses relacionamentos, as situações de violência contra o gênero feminino justificam especial proteção.

Além do mais, o ordenamento jurídico percebeu que a violência contra as mulheres não se tratava apenas da violência cometida contra as mulheres cisgênero, assim como a aplicabilidade da Lei 11.340/2006, mas também às mulheres transexuais, às travestis e às mulheres lésbicas e outros (TREVISAN, 2011).

No caso do internauta 8, a ideia de "aberrações comportamentais" remete ao pensamento patologizante da identidade trans (ARAÚJO; VIEIRA, 2010), considerada como algo diferente, temido e repudiado.

A partir das falas percebe-se a presença do pensamento de uma transfobia que busca excluir os direitos de uma minoria, baseando-se na premissa do funcionamento de leis cis, na qual a transexualidade é inferiorizada perante essa.

\section{Considerações Finais}

Perante os diversos espaços de interações sociais, as pessoas transexuais estão sofrendo com uma transfobia cristalizada. Os indivíduos que estão se distanciando de um caminho articuladamente estabelecido para os gêneros, estão sendo um a um retirados da vida em sociedade. Há exclusão das escolas, trabalhos, das ruas e por fim são retiradas/retirados da vida.

O discurso de ódio sempre existiu. O que acontece, com a internet, é que qualquer pessoa pode divulgar e ter uma audiência, não é preciso ser um líder. Outra coisa é o lado anônimo. Quem não tem coragem de dizer uma coisa assim na rua vai usar esse direito do anonimato, mas abusando dele. No meio digital, o discurso ganha mais poder, se propaga mais rapidamente e causa muito mais danos. É importante aceitar que o discurso de ódio on-line pode não só excluir, mas matar muitas pessoas (STYCER, 2016).

Os assassinatos são bastante recorrentes na população transexual. Os discursos de ódio proferidos nos comentários ora analisados demonstram a transfobia que ainda existe na sociedade e que acaba sendo exposta na internet por meio do "anonimato". Com esta 
pesquisa, foi possível compreendermos os altos índices de assassinatos das pessoas transexuais.

A partir dos comentários foi também possível analisar a existência de uma transfobia marcada por um teor considerado de ódio às pessoas transexuais que acabam sendo também revelados nos números de assassinatos.

Os discursos transfóbicos proferidos no ciberespaço, sem regulação ou filtro, geram e propagam mais violência. A violência é estendida para os outros espaços sociais, segregando e muitas vezes matando essas pessoas.

O presente estudo se caracterizou como um aporte inicial para se compreender as relações entre violência contra transexuais e ciberespaço, buscando entender os fenômenos envolvidos nessas relações. 


\section{REFERÊNCIAS}

AMARAL, D. M. “A psiquiatrização da transexualidade: análise dos efeitos do diagnóstico de transtorno de identidade de gênero nas práticas de saúde”. Rio de Janeiro, 2007. 129 f. Dissertação (Mestrado em Saúde Coletiva) - Instituto de Medicina Social, Universidade do Estado do Rio de Janeiro.

ARAÚJO, L. R. VIEIRA, L. L. F. A invenção da transexualidade. In: Transexualidade: Dos transtornos às experiências singulares. Recife, 2010. 123 f. Dissertação (Mestrado em Psicologia Clínica) - Centro de Ciências Biológicas e da Saúde, Universidade Católica de Pernambuco.

ÁVILA, T. A. P. Lei Maria da Penha. Uma análise dos novos instrumentos de proteção às mulheres. 2007. Disponível em: <

http://www.egov.ufsc.br/portal/sites/default/files/anexos/13477-13478-1-PB.pdf> Acesso em 30 set. 2017.

BARBOSA, B. R. S. N. Vida e morte (in) visíveis: Notas sobre o Feminicídio e sua Aplicabilidade para Mulheres Transexuais e Travestis. Alethes, Juiz de Fora, n.9, p. 162-172, 2015.

BARBOSA, B. R. S. N.; SILVA, L. V. "Os cães do inferno se alimentam de blasfêmia": religião e transfobia no ciberespaço. Ciencias Sociales y Religión/Ciências Sociais e Religião, v. 18, n. 24, p. 110-133, 2016.

BENTO, B. Nome social para pessoas trans: cidadania precária e gambiarra legal. Revista Semestral do Departamento e do Programa de Pós-Graduação em Sociologia da UFSCar, v. 4, n. 1, p. 165-182, 2014.

BENTO, B. A. M. O que é transexualidade?. São Paulo: Brasiliense, 2008.

BUTLER, J. Corpos que pesam: sobre os limites discursivos do "sexo". In: LOURO, Guacira Lopes. O corpo educado: pedagogias da sexualidade. Belo Horizonte: Autêntica, 1999.

CALIXTO, D. Educomunicação e redes sociais: caminhos para cidadania em meio ao esgotamento do diálogo e à escalada de ódio. In: Intercom - Sociedade Brasileira de Estudos Interdisciplinares da Comunicação XXXVIII Congresso Brasileiro de Ciências da Comunicação, Rio de Janeiro, RJ, p. 1-12, 2015.

CORRÊA, M. Do feminismo aos estudos de gênero no Brasil: um exemplo pessoal. Cadernos Pagu, n. 16, p. 13-30, 2001.

DIAS, M. B. Violência doméstica e as uniões homoafetivas. Jus Navigandi, v. 29, 2008.

GRUPO GAY DA BAHIA. Relatório 2016: assassinatos de LGBT no Brasil, Salvador, 2016. Disponível em: < https://homofobiamata.files.wordpress.com/2017/01/relatc3b3rio2016-ps.pdf >: Acesso em: 30 set. 2017.

JESUS, J. G.; ALVES, H. Feminismo transgênero e movimentos de mulheres transexuais. Revista Cronos, v. 11, n. 2, [s. p], 2012. 
JESUS, J. G. Orientações sobre identidade de gênero: conceitos e termos. Brasília. 2012.

JESÚS, B. M. A (des) naturalização do gênero e da sexualidade: algumas reflexões sobre o acesso das/dos transexuais à cidadania no Brasil. In: II Seminário de Pesquisa da Faculdade de Ciências Sociais. UFG, p.1-10, 2011.

LOURO, G. L. Gênero, sexualidade e educação: uma perspectiva pós-estruturalista. Petrópolis: Vozes, 2014.

MANTOVANI, F. 'Tenho muito medo de ele me matar', diz transexual espancada pelo ex. G1, São Paulo, 01 ago. 2016. Disponível em: < http://g1.globo.com/politica/noticia/2016/08/tenho-muito-medo-de-ele-me-matar-diztransexual-espancada-pelo-ex.html>. Acesso em: 20 ago. 2016.

MATÃO, M. E. L. et al. Representações sociais da transexualidade: perspectiva dos acadêmicos de Enfermagem e Medicina. Revista Baiana de Saúde Pública, v. 34, n. 1, p. 101-118, 2011.

MATOS, M. I. S. Estudos de gênero: percursos e possibilidades na historiografia contemporânea. Cadernos Pagu, n. 11, p. 67-75, 2013.

NARVAZ, M. G.; KOLLER, S. H. Metodologias feministas e estudos de gênero: articulando pesquisa, clínica e política. Psicologia em Estudo, v. 11, n. 3, p. 647-654, 2006.

OLIVEIRA JÚNIOR, I. B.; MAIO, E. R. Re/des/construindo in/diferenças: ax expulsão compulsória de estudantes trans do sistema escolar. Revista da FAEEBA-Educação e Contemporaneidade, v. 25, n. 45, p. 159-172, 2016.

PETRY, A. R.; MEYER, D. E. Transexualidade e heteronormatividade: algumas questões para a pesquisa. Textos \& Contextos, v. 10, n. 1, p. 193-198, 2011.

RICH, A. Heterossexualidade compulsória e existência lésbica. Bagoas: estudos gays: gêneros e sexualidades, v. 4, n. 5, p. 17-44, 2010.

SCAVONE, L. Estudos de gênero: uma sociologia feminista. Revista Estudos Feministas, v. 16, n. 1, p. 173-186, 2008.

STYCER, C. Niousha Roshani, antropóloga: 'O discurso de ódio on-line pode matar'. O globo, Rio de Janeiro, 09 jun. 2016. Disponível em: <

http://oglobo.globo.com/sociedade/conte-algo-que-nao-sei/niousha-roshani-antropologadiscurso-de-odio-on-line-pode-matar-19252102 >. Acesso em: 23set. 2016.

TRANSGENDER EUROPE'S TRANS MURDER MONITORING. 08 mai. 2015. Disponível em: < http://tgeu.org/tmm-idahot-update-2015/ >. Acesso em: 28 set. 2016.

TREVISAN, I. P. Femicídios no Rio Grande do Sul e a lei Maria da Penha. Porto Alegre, 2011. Monografia (Especialização em Educação, Sexualidade e Relações de Gênero) Faculdade de Educação, Universidade Federal do Rio Grande do Sul. 